\title{
Clinical And Economic Burden Of Eosinophilic COPD In A Large Retrospective US Cohort
}

This article was published in the following Dove Press journal:

International Journal of Chronic Obstructive Pulmonary Disease

\author{
Frank Trudo' \\ Lee Kallenbach ${ }^{2}$ \\ Joseph Vasey ${ }^{2}$ \\ Yen Chung $\mathbb{D}^{\prime}$ \\ Alan Wilk (iD ${ }^{2}$ \\ Lukas Slipski (iD) ${ }^{2}$ \\ Dan O'Brien² \\ Charlie Strange (iD ${ }^{3}$ \\ 'Respiratory and Inflammation \\ Therapeutic Area, AstraZeneca, \\ Wilmington, DE, USA; '2Life Sciences, \\ Practice Fusion, San Francisco, CA, USA: \\ ${ }^{3}$ Department of Medicine, Medical \\ University of South Carolina, Charleston, \\ SC, USA
}

Purpose: We sought to describe clinical and economic outcomes for COPD patients by blood eosinophil (EOS) count.

Methods: This retrospective cohort study of COPD patients used data from the Practice Fusion electronic medical records (EMR) database linked to Symphony Health Solutions transactional pharmacy, medical, outpatient, and inpatient claims data to evaluate COPD-related and all-cause health care resource utilization and cost in the 12-month period following the date of each patient's greatest recorded blood eosinophil count during the 27-month period from January 2014 to March 2016. A post-index moderate exacerbation was defined as an outpatient or emergency care visit for COPD and a prescription for oral corticosteroid and/or antibiotics within 10 days of the visit. Severe exacerbation was defined as an inpatient hospitalization with COPD as primary diagnosis. Results: Of 48,090 EMR patients, 39,939 (83.1\%) had a charge in the claims data both preand post-index (mean age 67.2 years, $58.3 \%$ female), $17,397(43.6 \%$ ) had $\mathrm{EOS} \geq 220$ cells $/ \mu \mathrm{L}$. Moderate and severe exacerbations were more frequent for patients with $\mathrm{EOS} \geq 220$ cells $/ \mu \mathrm{L}$ compared with those with EOS $<220$ cells $/ \mu \mathrm{L}$ (moderate: $6.8 \%$ vs $6.1 \%$, p $<0.05$; severe: $3.1 \%$ vs $2.5 \%, \mathrm{p}<0.001)$. After adjustment for baseline clinical characteristics, each 100-unit increase in EOS count was associated with a significant $2.24 \%$ increase in total all-cause costs and $4.54 \%$ increase in total COPD-related costs ( $\mathrm{p}<0.001$ for both). COPD-related costs were significantly greater for patients with an EOS count of $\geq 220$ cells $/ \mu \mathrm{L}$ compared with those with EOS $<220$ cells $/ \mu \mathrm{L}(\mathrm{p}<0.001)$. These costs appear to have been driven by a greater percentage of patients in the $\geq 220$ cells $/ \mu \mathrm{L}$ cohort with COPD-related resource use including hospitalization, office visits, ambulatory procedures and pharmacy prescriptions.

Conclusion: COPD patients with EOS counts $\geq 220$ cells $/ \mu \mathrm{L}$ were more likely to have had moderate or severe exacerbations and greater cost of care than those with EOS $<220$ cells $/ \mu \mathrm{L}$. Keywords: clinical phenotypes, electronic medical records, exacerbations, health care resource utilization, eosinophils

\section{Plain Language Summary}

Based on results and post hoc analyses of recent clinical trials, the 2019 Global Strategy for the Diagnosis, Management, and Prevention of COPD report now includes a paragraph on blood eosinophil counts stating "blood eosinophil counts can help clinicians estimate the likelihood of a beneficial preventive response to the addition of ICS to regular bronchodilator treatment and can be used as a biomarker in conjunction with clinical assessment when making decisions regarding ICS use". There is still need for real-world evidence among broader populations of COPD patients assessing the relationship between blood eosinophil counts and clinical characteristics, health care resource utilization, and costs. We evaluated four COPD subgroups with blood eosinophil counts of $<220, \geq 220, \geq 300, \geq 400$ cells $/ \mu \mathrm{L}$.
Correspondence: Frank Trudo AstraZeneca Pharmaceuticals, 1800 Concord Pike, Wilmington, DE 19897 , USA

Email Frank.Trudo@astrazeneca.com 
Our findings substantiate the relationship between blood eosinophils and health care resource utilization in a broad COPD patient population. COPD patients with blood eosinophil count $\geq 220$ cells $/ \mu \mathrm{L}$ were significantly more likely to have had moderate or severe exacerbations and greater cost of care than those with a blood eosinophil count $<220$ cells $/ \mu \mathrm{L}$.

We conclude that these data support the GOLD report and providers should obtain eosinophil counts for COPD risk stratification when making decisions regarding ICS use.

\section{Introduction}

The natural history of chronic obstructive pulmonary disease (COPD) includes progressive airflow obstruction and lung function decline, punctuated by exacerbations that are associated with increased mortality. ${ }^{1}$

The association between blood eosinophil count and these important clinical outcomes remains to be elucidated. ${ }^{2,3}$ Analyses from the Copenhagen General Population Study indicated that a circulating peripheral blood eosinophil count of $>340$ cells $/ \mu \mathrm{L}$ was associated with an overall increased risk of exacerbations and a two-fold increase in the risk of severe exacerbations. ${ }^{4} \mathrm{~A}$ claims-based analysis by Zeiger concluded that high blood eosinophil counts $\geq 300,400$, and 500 cells $/ \mu \mathrm{L}$ were an independent risk factor for future exacerbations in patients with COPD. ${ }^{5}$ In a recent electronic medical record (EMR) database analysis by Kerkhof et al, greater blood eosinophil counts $(>450$ cells $/ \mu \mathrm{L})$ were associated with treatment-resistant exacerbations. ${ }^{6}$ Two recent clinical trials, METREX and METREO, evaluated COPD exacerbations in relation to blood eosinophil counts $\geq 150$ cells $/ \mu \mathrm{L}$ at screening, or $\geq 300$ cells $/ \mu \mathrm{L}$ during the previous year with findings suggesting that eosinophilic airway inflammation contributed to COPD exacerbations. ${ }^{7}$ Another recent clinical trial (KRONOS) demonstrated a lower rate of moderate or severe exacerbations among patients treated with triple therapy with LAMA/LABA +ICS as compared with LAMA/LABA with treatment differences seen beginning at baseline eosinophil concentrations of $75-100$ cells $/ \mu \mathrm{L}^{8}{ }^{8}$ In addition, post-hoc analyses of three trials of budesonideformoterol compared to formoterol alone for patients with COPD found that blood eosinophil count predicted exacerbation risk and clinical response to ICS. ${ }^{9}$ These findings have been reviewed and are included in the most recent, 2019, Global Initiative for COPD strategy document for the management and prevention of COPD. ${ }^{10} \mathrm{~A}$ new section on blood eosinophil count has been added to this document and recommends the use of blood eosinophil counts when making decisions regarding ICS use. With respect to exacerbations, this document states that there is insufficient evidence to recommend blood eosinophils should be used to predict exacerbation risk. ${ }^{10}$

Cost associated with COPD is dependent on both the severity and frequency of exacerbations. Patients with severe exacerbations requiring ICU stays and recurrent care are responsible for a large percentage of total costs. For this reason, large-integrated databases are important for studying cost. Clinical data including eosinophil counts from EMR and health care utilization, and cost from claims databases linked together in a single-integrated database afford the opportunity to study large numbers of patients. Such a study was recently conducted for patients with asthma in the United Kingdom and it found increasing costs with increasing eosinophil counts (200, 300, 400, and 500 cells/ $\mu \mathrm{L}) .{ }^{11}$ Two recent US studies on patients with COPD have also found an increase in healthcare resource utilization with increasing eosinophil count. ${ }^{12,13}$

This retrospective, observational database study of COPD patients spanning multiple real-world US practice settings is the first comprehensive evaluation of the association of blood eosinophil counts with health care utilization and cost outcomes reflecting current clinical practice across the US. The aims of this cohort study were to describe patient characteristics, health care utilization and cost across groups with increasing blood eosinophil counts in a broadly representative COPD patient population. Our first objective was to describe patient clinical characteristics, including exacerbations, by blood eosinophil count. Our second objective was to determine the all-cause and COPD-related health care utilization and cost by blood eosinophil count categories.

\section{Methods}

\section{Data Source}

This retrospective cohort study utilized data from Practice Fusion's EMR database and from Symphony Health's administrative claims data. The Practice Fusion EMR database is a nationwide database consisting of clinical data sourced primarily from medical practices with 1 to 4 providers and includes patient charts, prescription history, and lab results. It covers approximately $6 \%$ of all ambulatory care 
from primary care and specialist practices in the United States. Practice Fusion's EMR patient population is comparable to the overall US population in terms of age, sex, and geographic distribution.

Symphony Health Solutions provides billing-related health care data including US pharmacy and medical claims submitted by approximately 30,000 pharmacies, 1,000 hospitals, 800 outpatient facilities, and 80,000 physician practices from across the US. The claims data are sourced from adjudication networks, service bureaus, and pharmacy organizations, and include claims from insured populations participating in commercial health plans as well as claims from patients participating in public insurance programs (eg, Medicaid and Medicare). The dataset is a national in scope and representative in terms of age, gender and insurance type. Claims data were the primary dataset for describing clinical outcomes including exacerbations and inhaled corticosteroid (ICS) use, as well as for the evaluation of patient healthcare utilization and cost in this study.

The two datasets were linked using Synoma, a proprietary matching engine that paired patient identifiers in the Practice Fusion and Symphony Health Solutions data. The resulting set of linked EMR and claims data underwent privacy certification before being made available for the purposes of this research. As a noninterventional, retrospective database study using a certified Health Insurance Portability and Accountability Act-compliant de-identified research database, approval by an institutional review board was not necessary.

\section{Study Design And Population}

Adult patients with a diagnosis of COPD anytime in the EMR data were assigned an index date set as the date of their greatest recorded blood eosinophil counts during the 27-month identification period between January 2014 and March 2016 (Figure 1). COPD-related and all-cause health care utilization and cost were evaluated for 12 months after the index date using integrated claims data (Figure 1). The integrated study population included EMR patients who had either a prescription, outpatient medical, or hospital charge in the 12 months prior to index (baseline period) and in the 12 months following index (follow-up period). Patients were excluded from the study cohort if they had a diagnosis of any malignant cancer - other than basal cell carcinoma or one of the following conditions: cystic fibrosis, allergic bronchopulmonary aspergillosis, sarcoidosis, acute or chronic eosinophilic pneumonia, eosinophilic granulomatosis with polyangiitis, parasitic infections, or idiopathic pulmonary fibrosis. Study subgroups were defined by categorizing patients based on their index blood eosinophil count.

\section{Exposure Measures}

Blood eosinophil count at index date was assessed as both a continuous measure and as a categorical variable based on four non-exclusive groups: $<220, \geq 220, \geq 300, \geq 400$. The four groups selected are similar to the four groups reported by Kerkhof et al in a recent study of maximum blood eosinophil counts for patients with severe-uncontrolled eosinophilic asthma. ${ }^{11}$ For regression models, we
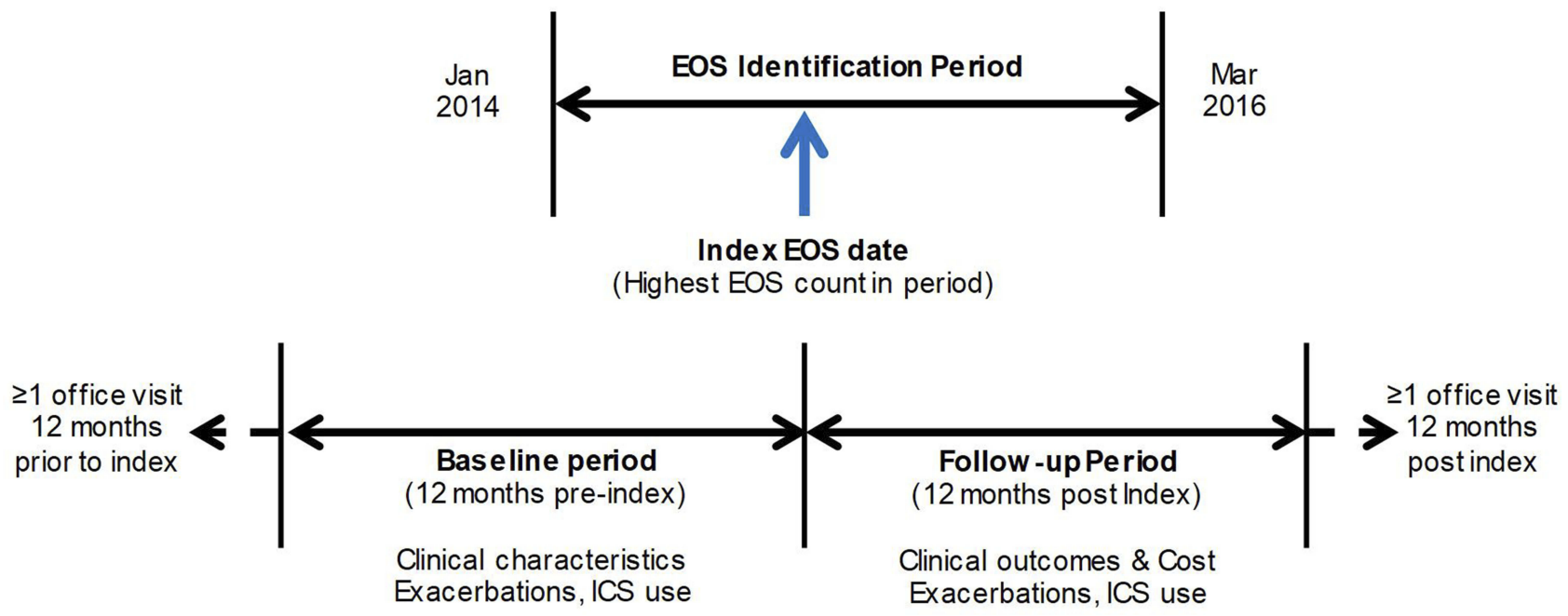

Figure I Study design.

Abbreviations: EOS, eosinophil count; ICS, inhaled corticosteroid. 
used eosinophil count as either a continuous measure showing percentage change in cost for each 100 cells $/ \mu \mathrm{L}$ increase in eosinophil count or as a dichotomous measure based on the lowest of the three descriptive cutoffs $\geq 220$ cells $/ \mu \mathrm{L}$ compared to $<220$ cells $/ \mu \mathrm{L}$.

\section{Clinical Measures}

Patient-level characteristics were derived from the EMR data, including demographic and clinical characteristics, comorbidities including asthma and calculation of the Charlson Comorbidity Index (CCI), office visits, and prescription history. For time-sensitive characteristics, documentation closest to the index date was used. Covariate measures derived from the integrated dataset included the occurrence of moderate and severe COPD exacerbations, COPD-related costs, and ICS and systemic corticosteroid use.

Clinical outcomes were assessed in the 12 months postindex follow-up period. Moderate exacerbations were defined as an outpatient office, emergency department (ED), or urgent care visit with a diagnosis of COPD and a pharmacy prescription claim for an oral corticosteroid (OCS) and/or antibiotics on the same day as or within 10 days after the visit. A severe exacerbation was defined as a COPD-related inpatient hospitalization with a primary diagnosis of COPD. ED visits that resulted in hospitalization were categorized as severe. ${ }^{14,15}$ Because a patient could have multiple events in a single exacerbation episode, all exacerbation events recorded within 14 days were attributed to and counted as one exacerbation event.

\section{Health Care Costs And Utilization}

The costs attributable to inpatient hospitalizations, ED visits, outpatient office visits, outpatient procedures, and pharmacy prescriptions were compiled and reported as COPD-related and all-cause (ie, due to any condition). COPD-related costs included the costs of events that were linked to a COPD diagnosis code as a primary diagnosis for inpatient stays and any diagnosis position for other services. All-cause health care costs included the costs of all health care encounters regardless of reason or diagnosis. The presence of a visit (any vs none) and the number of visits by type of service (inpatient hospitalization, ED, outpatient/office visit) were captured to define utilization. As with cost calculations, a visit was considered COPD-related if the medical claim contained an applicable COPD diagnosis code; a primary diagnosis was required for inpatient stays, with a claim in any position for other service locations.

\section{Statistical Analyses}

Tabulation of summary statistics and all statistical analyses were conducted with SAS (SAS 9.4, SAS Institute, Cary, NC). $\mathrm{P}$-values were calculated using chi-squared tests for categorical variables and ANOVA for continuous variables, accommodating for heteroskedasticity using the Welch test as needed. Statistical tests were two-sided, with an $\alpha$-level of 0.05 for statistical significance.

Regression models were implemented by first looking at the potential univariate effect of covariates on cost outcomes. Exacerbations, smoking status, ICS treatment, CCI, asthma, nasal polyposis, baseline overall resource cost, and chronic OCS use were considered as covariates and were tested as univariate predictors of cost outcomes. If a covariate was found to be a univariate predictor, it was included into a regression model with a log link and a gamma distribution as a covariate adjustment for the effect of blood eosinophil count on cost outcomes. Covariates were assessed in this model via stepwise deletion, with blood eosinophil counts being held in each model as a predictor of cost outcomes.

For all objectives, missing data were counted and reported for each variable. In the event of missing data when comparing descriptive variables, pairwise deletion was used for statistical tests, reported counts of missing data were used for counts, and all non-missing data were used for descriptive statistics. When utilizing the adjusted regression models, missing data were handled via list-wise deletion.

\section{Results}

\section{Patient Population}

In the EMR database, 155,460 of 886,784 patients (17.5\%) with a diagnosis of COPD had a recorded blood eosinophil count between January 1, 2014, and March 31, 2016. A total of 48,090 (31\% of patients with an eligible blood eosinophil count) met the full EMR study eligibility criteria (Figure 2). The final linked study population consisted of the 39,939 EMR patients $(83 \%)$ who had either a prescription, outpatient medical, or hospital charge in the 12 months prior to index and in the 12 months following index.

\section{Eosinophil Counts}

The mean index blood eosinophil counts for the 48,090 patients in the EMR data set and the 39,939 patients in the integrated dataset were $252.2 \pm 172.1$ and $252.3 \pm 171.8$ cells $/ \mu \mathrm{L}$, respectively (Table 1 ). The mean eosinophil counts for the four blood eosinophil subgroups were 
essentially the same for patients in the EMR dataset and patients in the integrated data set (Table 1). Analysis of within patient variability was not conducted due to limitations in such an analysis based on the current study design.

Eosinophil counts were evaluated in the 12-month periods before (baseline) and after (follow-up) the index value, not including index value, for patients who had several eosinophil counts recorded. Of patients in the integrated data set, 15,871 (39.7\%) had a baseline blood eosinophil count available and 21,047 (52.7\%) had a follow-up blood eosinophil count available (Table 1). The overall mean baseline and follow-up blood eosinophil counts were 222.0 and 218.5 cells $/ \mu \mathrm{L}$, respectively (Table 1 ). Within each blood eosinophil subgroup, mean baseline and follow-up eosinophil counts were also similar (Table 1).

\section{Demographics And Baseline Clinical Characteristics}

The average age of the study population was $67.2 \pm 11.4$ years and was lowest in the $<220$ cells $/ \mu \mathrm{L}$ subgroup

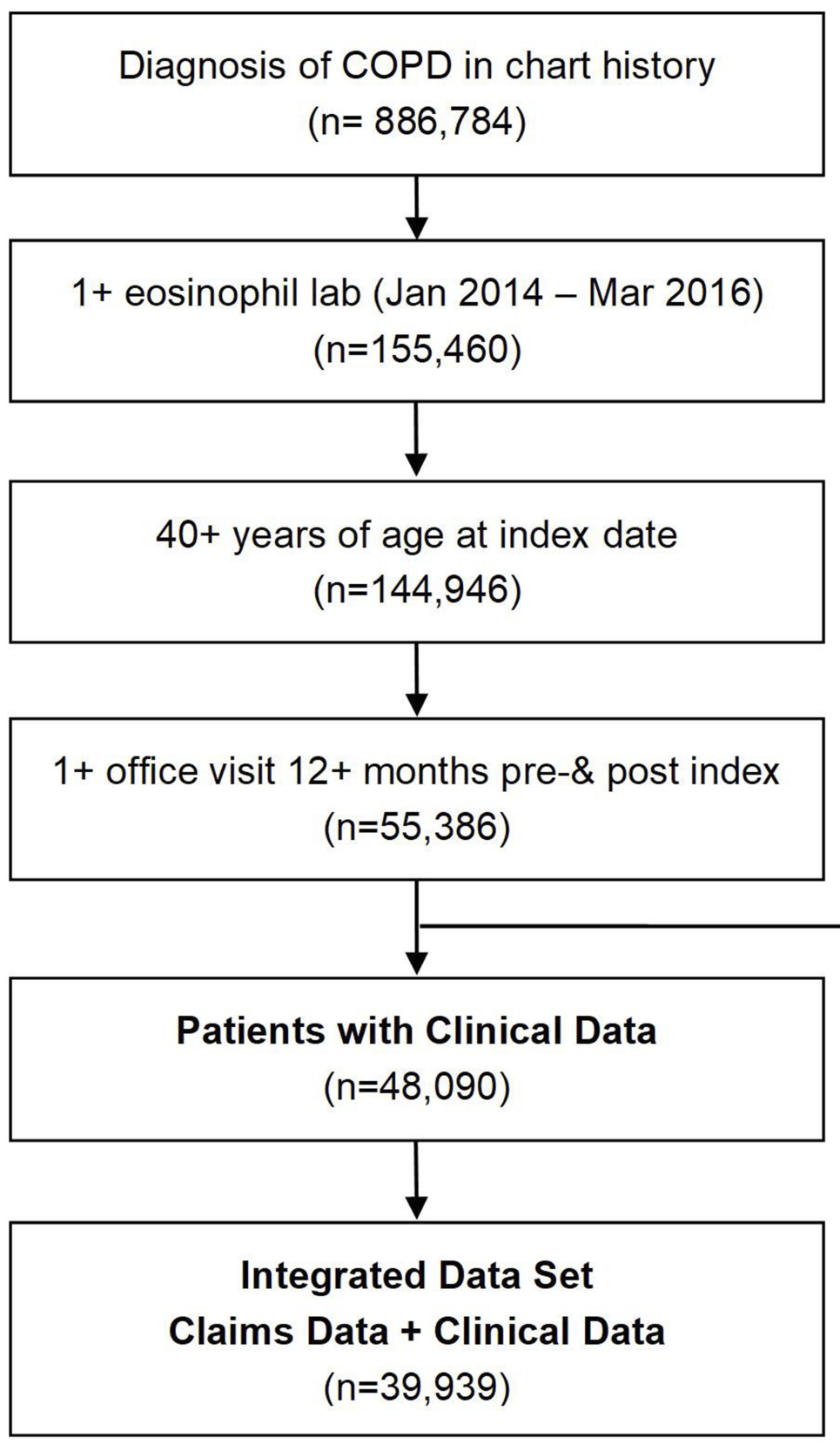

Diagnosis of Cancer, Cystic Fibrosis, Sarcoidosis, Parasitic Infection, Allergic Bronchopulmonary Aspergillosis, Acute or Chronic Eosinophilic Pneumonia, Eosinophilic Granulomatosis with Polyangiitis, or Idiopathic Pulmonary Fibrosis. $(n=7,296)$

Figure 2 Eligibility criteria. EMR patient cohort $(n=48,090)$ linked to claims $(n=39,939)$.

Abbreviations: COPD, chronic obstructive pulmonary disease; EMR, electronic medical record. 
Table I Eosinophil Levels: Indexa, Baseline, And Follow-Up

\begin{tabular}{|c|c|c|c|c|c|}
\hline \multirow[t]{3}{*}{ Time Period } & \multicolumn{5}{|c|}{ Index Eosinophil Group } \\
\hline & All & $<220$ cells $/ \mu \mathrm{L}$ & $\geq 220 \mathrm{cells} / \mu \mathrm{L}$ & $\geq 300$ cells $/ \mu \mathrm{L}$ & $\geq 400$ cells $/ \mu \mathrm{L}$ \\
\hline & $(n=48,090)$ & $(n=27,2 I I)$ & $(n=20,879)$ & $(n=16,737)$ & $(n=8,946)$ \\
\hline \multirow{2}{*}{\multicolumn{6}{|c|}{$\begin{array}{l}\text { EMR Patients } \\
\text { Index }\end{array}$}} \\
\hline & & & & & \\
\hline $\mathrm{N}$ & 48,090 & 27,211 & 20,879 & 16,737 & 8,946 \\
\hline Mean (SD) & $252.2(172.1)$ & I $38.9(58.1)$ & 399.8 (159.2) & $435.6(158.2)$ & $538.8(152.6)$ \\
\hline \multicolumn{6}{|l|}{ Baseline } \\
\hline $\mathrm{N}$ & 19,178 & 8,870 & 10,308 & 8,296 & 4,673 \\
\hline Mean (SD) & $229.4(162.3)$ & $129.5(64.5)$ & $333.9(168.0)$ & $36 I .4(173.2)$ & $434.0(190.2)$ \\
\hline \multicolumn{6}{|l|}{ Follow-up } \\
\hline$N$ & 25,473 & 13,139 & 12,334 & 10,075 & 5,522 \\
\hline Mean (SD) & $200.1(141.5)$ & I2I.3 (74.2) & $273.2(149.5)$ & $291.3(153.9)$ & $343.0(168.6)$ \\
\hline \multicolumn{6}{|c|}{ Integrated Patients $^{c}$} \\
\hline \multicolumn{6}{|l|}{ Index } \\
\hline $\mathrm{N}$ & 39,939 & 22,542 & 17,397 & 13,913 & 7,440 \\
\hline Mean (SD) & $252.3(171.8)$ & I39.0 (58.1) & $399.2(158.6)$ & $435.2(157.6)$ & $538.0(151.9)$ \\
\hline \multicolumn{6}{|l|}{ Baseline } \\
\hline $\mathrm{N}$ & $|5,87|$ & 7,348 & 8,523 & 6,854 & 3,855 \\
\hline Mean (SD) & $222.0(156.0)$ & $122.5(67.2)$ & $296.1(161.9)$ & $318.5(167.6)$ & $377.0(184.1)$ \\
\hline \multicolumn{6}{|l|}{ Follow-up } \\
\hline $\mathrm{N}$ & 21,047 & 10,820 & 10,227 & 8,332 & 4,572 \\
\hline Mean (SD) & $218.5(154.4)$ & I25.I (68.6) & $300.8(162.0)$ & 322.7 (167.2) & $382.6(184.2)$ \\
\hline
\end{tabular}

Notes: ${ }^{a}$ Index eosinophil level was required; ${ }^{b}$ patients with data from the EMR data source; ${ }^{c}$ patients with data from both the EMR data source and the claims data source.

(Table 2). More than half $(\mathrm{n}=23,271[58.3 \%])$ of patients were female, with the percentages decreasing from the $<220$ cells $/ \mu \mathrm{L}$ subgroup $(62.0 \%)$ to the $\geq 400$ cells $/ \mu \mathrm{L}$ subgroup $(50.0 \%)$ (Table 2). The percentages of current smokers also decreased from the $<220$ cells $/ \mu \mathrm{L}$ subgroup (30.8\%) to the $\geq 400$ cells $/ \mu \mathrm{L}$ subgroup (27.5\%) (Table 2 ). Conversely, the percentages of former smokers were lowest in the $<220$ cells $/ \mu \mathrm{L}$ subgroup (40.1\%) and highest in the $\geq 400$ cells/ $\mu \mathrm{L}$ subgroup ( $45.0 \%$ ) (Table 2 ).

The mean CCI in the overall study population was $2.6 \pm 1.9$, the percentage of patients with a comorbid diagnosis of asthma was $18.1 \%$, the study population had an average of $8.4 \pm 7.4$ outpatient visits per patient in the 12-month baseline period, the number of patients with ICS use was $6,933(17.4 \%)$, the percentages of patients with an occurrence of any exacerbation, moderate or severe were $2,858(7.2 \%)$, and baseline COPDrelated costs were US $\$ 3,671 \pm \$ 19,488$. For all these characteristics, the percentages of patients exhibiting the characteristic, or the mean value for the characteristic was consistently lowest for patients in the $<220$ cells $/ \mu \mathrm{L}$ subgroup and greatest for highest the $\geq 400$ cells/ $\mu \mathrm{L}$ subgroup (Table 2 ).

\section{Clinical Outcomes - Exacerbations And ICS Use}

The percentages of patients with moderate or severe exacerbations in the 12-month follow-up period were all greater for the $\geq 220$ cells $/ \mu \mathrm{L}, \geq 300$ cells $/ \mu \mathrm{L}$, and $\geq 400$ cells $/ \mu \mathrm{L}$ groups compared with the $<220$ cells $/ \mu \mathrm{L}$ group $(\mathrm{p}<0.05$ for all; Table 3). Similarly, a higher percentage of patients were placed on new ICS treatment in the follow-up period across the 3 higher eosinophil groups compared to the $<220$ cells $/ \mu \mathrm{L}$ group ( $<<0.001$ for all; Table 3 ).

\section{Health Care Resource Use}

The average utilization per patient for patients of both COPDrelated and all-cause health care resource use was all greater for the $\geq 220$ cells $/ \mu \mathrm{L}, \geq 300$ cells $/ \mu \mathrm{L}$, and $\geq 400$ cells $/ \mu \mathrm{L}$ subgroups compared with the $<220$ cells $/ \mu \mathrm{L}$ subgroup except for ED use which was only greater in the $\geq 400$ cells $/ \mu$ L subgroup for COPD-related healthcare resource use. Even though the 
Table 2 Baseline Demographic \& Clinical Characteristics

\begin{tabular}{|c|c|c|c|c|c|}
\hline \multirow[t]{3}{*}{ Variable } & \multicolumn{5}{|c|}{ Index Eosinophil Group } \\
\hline & All & $<220$ cells $/ \mu \mathrm{L}$ & $\geq 220$ cells $/ \mu \mathrm{L}$ & $\geq 300$ cells $/ \mu \mathrm{L}$ & $\geq 400$ cells $/ \mu \mathrm{L}$ \\
\hline & $(n=39,939)$ & $(n=22,542)$ & $(n=17,397)$ & $(n=|3,9| 3)$ & $(n=7,440)$ \\
\hline Age, Mean (SD) & $67.2(11.4)$ & $66.5(11.5)$ & $68.1(11.2)$ & $68.2(11.2)$ & $68.5(11.2)$ \\
\hline BMI, Mean (SD) & $29.8(7.6)$ & $29.5(7.6)$ & $30.1(7.6)$ & $30.1(7.6)$ & $30.0(7.4)$ \\
\hline Sex (Female) & $23,27 \mid(58.3)$ & $13,968(62.0)$ & $9,303(53.5)$ & $7,342(52.8)$ & $3,719(50.0)$ \\
\hline \multicolumn{6}{|l|}{ Smoking Status } \\
\hline Current & II,909 (29.8) & $6,943(30.8)$ & $4,966(28.5)$ & $3,989(28.7)$ & $2,044(27.5)$ \\
\hline Former & $16,646(41.7)$ & $9,039(40.1)$ & $7,607(43.7)$ & $6,117(44.0)$ & $3,346(45.0)$ \\
\hline Never & $8,636(21.6)$ & $5,010(22.2)$ & $3,626(20.8)$ & $2,868(20.6)$ & I,553 (20.9) \\
\hline Unknown & $376(0.9)$ & $225(1.0)$ & $|5|(0.9)$ & $108(0.8)$ & $58(0.8)$ \\
\hline Not Reported & $2,372(5.9)$ & I,325 (5.9) & $\mathrm{I}, 047(6.0)$ & $831(6.0)$ & $439(5.9)$ \\
\hline \multicolumn{6}{|l|}{ Charlson Comorbidity Index ${ }^{a}$} \\
\hline Mean (SD) & $2.6(1.9)$ & $2.5(1.8)$ & $2.8(2.0)$ & $2.8(2.0)$ & $2.9(2.0)$ \\
\hline \multicolumn{6}{|l|}{ Diagnosis Count ${ }^{\mathrm{b}}$} \\
\hline I & $14,143(35.4)$ & $8,715(38.7)$ & $5,428(31.2)$ & $4,263(30.6)$ & $2,183(29.3)$ \\
\hline $2-3$ & I5,733 (39.4) & $8,859(39.3)$ & $6,874(39.5)$ & $5,528(39.7)$ & $2,901(39.0)$ \\
\hline $4+$ & $10,06 \mid(25.2)$ & $4,968(22.0)$ & $5,093(29.3)$ & $4,120(29.6)$ & $2,354(31.6)$ \\
\hline \multicolumn{6}{|l|}{ Diagnosis } \\
\hline Anxiety & II,688 (29.3) & $6,808(30.2)$ & $4,880(28.1)$ & $3,875(27.9)$ & $2,022(27.2)$ \\
\hline Asthma & $7,227(18.1)$ & 3,855 (I7.I) & $3,372(19.4)$ & $2,754(19.8)$ & $\mathrm{I}, 58 \mathrm{I}(2 \mathrm{I} .3)$ \\
\hline Depression & $10,289(25.8)$ & $5,799(25.7)$ & $4,490(25.8)$ & $3,618(26.0)$ & $1,902(25.6)$ \\
\hline Physician Visits, mean (SD) & $8.4(7.4)$ & $8.2(7.1)$ & $8.6(7.8)$ & $8.6(7.9)$ & $8.8(8.3)$ \\
\hline \multicolumn{6}{|l|}{ Corticosteroid Use $(I+R x)$} \\
\hline ICS use & $6,933(17.4)$ & $3,649(16.2)$ & $3,284(18.9)$ & $2,685(19.3)$ & I,542 (20.7) \\
\hline SCS use & $779(2.0)$ & $446(2.0)$ & 333 (1.9) & $276(2.0)$ & $|5|(2.0)$ \\
\hline Mod. to Sev. Exacerbation $(I+)$ & $2,858(7.2)$ & $\mathrm{I}, 487(6.6)$ & I,37I (7.9) & $\mathrm{I}, 094(7.9)$ & $635(8.5)$ \\
\hline Baseline COPD Costs, mean (SD) & $\$ 3,67 \mathrm{I}(\$ 19.5 \mathrm{k})$ & $\$ 3,263(\$ 16.6 k)$ & $\$ 4,199(\$ 22.7 k)$ & $\$ 4,3$ II (\$24.0k) & $\$ 4,634(\$ 27.3 \mathrm{k})$ \\
\hline
\end{tabular}

Notes: Data are reported as $\mathrm{n}(\%)$ unless otherwise specified. ${ }^{\mathrm{a}}$ The Quan Enhanced Comorbidity score ranges from 0 to 37; ${ }^{\mathrm{b}}$ count of co-morbid conditions included in Quan Enhanced Comorbidity score.

Abbreviations: ICS, inhaled corticosteroid; SCS, systemic corticosteroid.

absolute event rates are relatively low, the percent difference between the $<220$ cells $/ \mu \mathrm{L}$ and the $\geq 220$ cells $/ \mu \mathrm{L}$ groups was $26.4 \%$ for all-cause hospitalization and $32.7 \%$ for COPDrelated hospitalization. In addition, the utilization per patient for all-cause and COPD-related healthcare resources generally tended to increase slightly across increasing eosinophil count subgroups, $<220, \geq 220, \geq 300, \geq 400$ (Tables 4 and 5).

\section{All-Cause And COPD-Related Costs}

As one would expect, patterns of overall cost generally followed those of utilization, with overall costs tending to increase across the four eosinophil subgroups for both allcause and COPD-related costs. For the $\geq 220$ compared to $<220$ cells/ $\mu \mathrm{L}$ subgroups, overall COPD-related costs were
$24 \%$ greater and overall all-cause costs were 17\% greater. Hospital and pharmacy costs were the significant contributors for COPD-related costs and hospital and outpatient visits/ procedures were the significant contributors for All-cause costs (Table 6).

\section{Eosinophils And Health Care Resource Use And Costs}

Regression models were run for overall, hospital, and ED, all-cause and COPD-related costs, with eosinophil count as either a continuous measure showing percentage change in cost for each 100 cells $/ \mu \mathrm{L}$ increase in eosinophil count or as a dichotomous measure based on $<220$ and $\geq 220$ cells $/ \mu \mathrm{L}$. Models were adjusted for demographics and 
Table 3 Clinical Outcomes

\begin{tabular}{|c|c|c|c|c|}
\hline \multirow[t]{3}{*}{ COPD-Related Outcome } & \multicolumn{4}{|c|}{ Index Eosinophil Group } \\
\hline & $<220$ cells $/ \mu \mathrm{L}$ & $\geq 220$ cells $/ \mu \mathrm{L}$ & $\geq 300$ cells $/ \mu \mathrm{L}$ & $\geq 400$ cells $/ \mu \mathrm{L}$ \\
\hline & $(n=22,542)$ & $(n=17,397)$ & $(n=|3,9| 3)$ & $(n=7,440)$ \\
\hline \multicolumn{5}{|l|}{ Moderate Exacerbation } \\
\hline Patients & $1,370(6.1 \%)$ & $\mathrm{I}, \mathrm{I} 77(6.8 \%) \dagger$ & $950(6.8 \%) \dagger$ & $536(7.2 \%) \dagger$ \\
\hline Events (total) & 2,111 & $\mathrm{I}, 820$ & $\mathrm{I}, 474$ & 836 \\
\hline Events $^{\mathrm{a}}$ (per patient $\mathrm{t}^{\mathrm{b}}$ ) & 0.094 & $0.105 \dagger$ & $0.106 \dagger$ & $0.112 \dagger$ \\
\hline \multicolumn{5}{|l|}{ Severe Exacerbation } \\
\hline Patients & $554(2.5 \%)$ & $54 \mid(3.1 \%)^{\ddagger}$ & $439(3.2 \%)^{\ddagger}$ & $256(3.4 \%)^{\ddagger}$ \\
\hline Events (total) & 675 & 669 & 556 & 329 \\
\hline Events (per patient) & 0.03 & $0.038^{\ddagger}$ & $0.04^{\ddagger}$ & $0.044^{\ddagger}$ \\
\hline \multicolumn{5}{|l|}{ ICS Treatment (Follow-Up) } \\
\hline No & $16,763(74.4 \%)$ & $12,202(70.1 \%)^{\ddagger}$ & $9,680(69.6 \%)^{\ddagger}$ & $5,048(67.8 \%)^{\ddagger}$ \\
\hline Yes, new in follow-up & $2,130(9.4 \%)$ & $1,911(11.0 \%)^{\ddagger}$ & I,548 (II.1\%) & $850(11.4 \%)^{\ddagger}$ \\
\hline
\end{tabular}

Notes: Statistical significance is indicated as ${ }^{\ddagger} \mathrm{p}<0.00$ I; $\nmid \mathrm{p}<0.05$ ( $<220$ vs $\geq 220, \geq 300, \geq 400$ cells/ $/ \mathrm{L}$ ). ${ }^{2}$ values are mean unless otherwise specified; ${ }^{\mathrm{b}}$ events per patient is the rate of events per patient for all patient in the category.

Table 4 Healthcare Resource Use - All-Cause

\begin{tabular}{|c|c|c|c|c|}
\hline \multirow[t]{3}{*}{ COPD-Related Outcome } & \multicolumn{4}{|c|}{ Index Eosinophil Group } \\
\hline & $<220$ cells $/ \mu \mathrm{L}$ & $\geq 220$ cells $/ \mu \mathrm{L}$ & $\geq 300$ cells $/ \mu \mathrm{L}$ & $\geq 400$ cells $/ \mu \mathrm{L}$ \\
\hline & $(n=22,542)$ & $(n=17,397)$ & $(n=|3,9| 3)$ & $(n=7,440)$ \\
\hline \multicolumn{5}{|l|}{ Inpatient Hospitalizations } \\
\hline Patients & I,405 (6.2\%) & $1,260(7.2 \%)^{\ddagger}$ & $1,017(7.3 \%)^{\ddagger}$ & $577(7.8 \%)^{\ddagger}$ \\
\hline Events (total) & 2,490 & 2,412 & 1,935 & $\mathrm{I}, 06 \mathrm{I}$ \\
\hline Events $^{\mathrm{a}}$ (per patient ${ }^{\mathrm{b}}$ ) & $0.110(0.5)$ & $0.139(0.7)^{\ddagger}$ & $0.139(0.7)^{\ddagger}$ & $0.143(0.7)^{\ddagger}$ \\
\hline \multicolumn{5}{|l|}{ ED Visits } \\
\hline Patients & $3,626(16.1 \%)$ & $2,768(15.9 \%)$ & $2,245(16.1 \%)$ & $1,206(16.2 \%)$ \\
\hline Events (total) & 9,064 & 6,644 & 5,392 & 2,926 \\
\hline Events (per patient) & $0.402(1.4)$ & $0.382(1.5)$ & $0.388(1.5)$ & $0.393(1.4)$ \\
\hline \multicolumn{5}{|l|}{ Outpatient Office Visits/Procedures } \\
\hline Patients & $17,770(78.8 \%)$ & $13,938(80.1 \%) \dagger$ & II, I83 (80.4\%) $)^{\ddagger}$ & $6,013(80.8 \%)^{\ddagger}$ \\
\hline Events (total) & 860,898 & 710,083 & 571,186 & 316,259 \\
\hline Events (per patient) & $38.2(65.8)$ & $40.8(72.1)^{\ddagger}$ & $4 \mathrm{I} . \mathrm{I}(73.5)^{\ddagger}$ & $42.5(78.0)^{\ddagger}$ \\
\hline \multicolumn{5}{|l|}{ Pharmacy Use } \\
\hline Patients & $21,598(95.8 \%)$ & $16,687(95.9 \%)$ & 13,354 (96.0\%) & 7,146 (96.0\%) \\
\hline Events (total) & 924,360 & 754,155 & 609,914 & 328,540 \\
\hline Events (per patient) & $41(39.5)$ & $43.3(40.0)^{\ddagger}$ & $43.8(39.8)^{\ddagger}$ & $44.2(40.0)^{\ddagger}$ \\
\hline
\end{tabular}

Notes: Statistical significance is indicated as ${ }^{\dagger} \mathrm{p}<0.00 \mathrm{I} ; \mathrm{t} p<0.05$ ( $<220 \mathrm{vs} \geq 220, \geq 300, \geq 400$ cells/ $\mu \mathrm{L}$ ). ${ }^{2}$ values are mean (SD) unless otherwise specified; ${ }^{b}$ events per patient is the rate of events per patient for all patient in the category.

baseline clinical characteristics including age, sex, smoking status, comorbid asthma, CCI, SCS and ICS use, and baseline COPD-related costs and exacerbations.

Blood eosinophil count had a statistically significant impact on all-cause costs overall, all-cause hospital costs, and overall COPD-related cost for both the continuous and dichotomous eosinophil measures $(\mathrm{p}<0.001)$. For the continuous measure models, each 100-cell increase in blood eosinophil count was associated with a $2.2 \%$ increase in all-cause cost, a $4.8 \%$ increase in hospital all-cause, and a $4.5 \%$ increase in overall COPD-related cost (Figure 3). For the dichotomous eosinophil count models, eosinophil count above 220 cells/uL 
Table 5 Healthcare Resource Use - COPD-Related

\begin{tabular}{|c|c|c|c|c|}
\hline \multirow[t]{3}{*}{ COPD-Related Outcome } & \multicolumn{4}{|c|}{ Index Eosinophil Group } \\
\hline & $<220$ cells $/ \mu \mathrm{L}$ & $\geq 220 \mathrm{cells} / \mu \mathrm{L}$ & $\geq 300$ cells $/ \mu \mathrm{L}$ & $\geq 400$ cells $/ \mu \mathrm{L}$ \\
\hline & $(n=22,542)$ & $(n=17,397)$ & $(n=|3,9| 3)$ & $(n=7,440)$ \\
\hline \multicolumn{5}{|l|}{ Inpatient Hospitalizations } \\
\hline Patients & $671(3.0 \%)$ & $658(3.8 \%)^{\ddagger}$ & $531(3.8 \%)^{\ddagger}$ & $298(4.0 \%)^{\ddagger}$ \\
\hline Events (total) & 1,094 & $\mathrm{I}, 137$ & 916 & 513 \\
\hline Events $^{\mathrm{a}}$ (per patient ${ }^{\mathrm{b}}$ ) & $0.049(0.3)$ & $0.065(0.4)^{\ddagger}$ & $0.066(0.5)^{\ddagger}$ & $0.069(0.5)^{\ddagger}$ \\
\hline \multicolumn{5}{|l|}{ ED Visits } \\
\hline Patients & $827(3.7 \%)$ & $693(4.0 \%)$ & $557(4.0 \%)$ & $318(4.3 \%) \dagger$ \\
\hline Events (total) & $\mathrm{I}, 480$ & $|, 25|$ & 1,010 & 632 \\
\hline Events (per patient) & $0.066(0.5)$ & $0.072(0.6)$ & $0.073(0.6)$ & $0.085(0.7) \dagger$ \\
\hline \multicolumn{5}{|c|}{ Outpatient Office Visits/Procedures } \\
\hline Patients & 6,435 (28.5\%) & $5,429(31.2 \%)^{\ddagger}$ & $4,372(31.4 \%)^{\ddagger}$ & $2,410(32.4 \%)^{\ddagger}$ \\
\hline Events (total) & 110,336 & 98,255 & 79,554 & 45,415 \\
\hline Events (per patient) & $4.9(16.3)$ & $5.6(21.3)^{\ddagger}$ & $5.7(22.1)^{\ddagger}$ & $6.1(25.2)^{\ddagger}$ \\
\hline \multicolumn{5}{|l|}{ Pharmacy Use } \\
\hline Patients & $17,287(76.7 \%)$ & $13,697(78.7 \%)^{\ddagger}$ & II,003 (79.1\%) & $5,917(79.5 \%)^{\ddagger}$ \\
\hline Events (total) & 137,775 & 116,637 & 95,414 & 53,838 \\
\hline Events (Per patient) & $6.1(8.9)$ & $6.7(9.1)^{\ddagger}$ & $6.9(9.3)^{\ddagger}$ & $7.2(9.7)^{\ddagger}$ \\
\hline
\end{tabular}

Notes: Statistical significance is indicated as ${ }^{\dagger} \mathrm{p}<0.001$; $\nmid \mathrm{p}<0.05$ ( $<220 \mathrm{vs} \geq 220, \geq 300, \geq 400$ cells/ $\left.\mu \mathrm{L}\right)$. ${ }^{2}$ values are mean (SD) unless otherwise specified; ${ }^{b}$ events per patient is the rate of events per patient for all patient in the category.

Table 6 Healthcare Cost - All-Cause \& COPD-Related Cost (Per Patient)

\begin{tabular}{|c|c|c|c|c|}
\hline \multirow[t]{3}{*}{ COPD-Related Outcome } & \multicolumn{4}{|c|}{ Index Eosinophil Group } \\
\hline & $<220$ cells $/ \mu \mathrm{L}$ & $\geq 220$ cells $/ \mu \mathrm{L}$ & $\geq 300$ cells $/ \mu \mathrm{L}$ & $\geq 400$ cells $/ \mu \mathrm{L}$ \\
\hline & $(n=22,542)$ & $(n=17,397)$ & $(n=|3,9| 3)$ & $(n=7,440)$ \\
\hline \multicolumn{5}{|l|}{ All-Cause Cost } \\
\hline Overall $^{\mathrm{a}}$ & $\$ 21,049(59,014)$ & $\$ 24,670(72,026)^{\ddagger}$ & $\$ 24,935(72,169)^{\ddagger}$ & $\$ 26,199(80,476)^{\ddagger}$ \\
\hline Hospitalization/inpatient & $\$ 4,837(31,999)$ & $\$ 6,524(44,676)^{\ddagger}$ & $\$ 6,457(42,300)^{\ddagger}$ & $\$ 7,126(46,786)^{\ddagger}$ \\
\hline ED visits & $\$ 427(1,649)$ & $\$ 445(1,9 \mid 8)$ & $\$ 446(I, 84 I)$ & $\$ 466(1,929)$ \\
\hline Outpatient visits/procedures & $\$ 10,282(37,190)$ & $\$ 11,908(47,094)^{\ddagger}$ & $\$|2| 4 \mid,(50,096)^{\ddagger}$ & $\$ 12,876(56,685)^{\ddagger}$ \\
\hline Pharmacy & $\$ 5,503(20,760)$ & $\$ 5,793(12,365)$ & $\$ 5,891(12,430) \dagger$ & $\$ 5,731(10,010)$ \\
\hline \multicolumn{5}{|l|}{ COPD-Related Cost } \\
\hline Overall & $\$ 4,357(22,884)$ & $\$ 5,407(28,402)^{\ddagger}$ & $\$ 5,491(28,974)^{\ddagger}$ & $\$ 5,774(31,376)^{\ddagger}$ \\
\hline Hospitalization/inpatient & $\$ 2,065(19,462)$ & $\$ 2,764(24,630) \dagger$ & $\$ 2,79 \mid(25,206) \dagger$ & $\$ 3,011(27,516) \dagger$ \\
\hline ED visits & $\$ 80(624)$ & $\$ 95(906)$ & $\$ 94(817)$ & $\$ 112(1,001) \dagger$ \\
\hline Outpatient visits/procedures & $\$ 1,316(7,125)$ & $\$ 1,532(8,367)^{\ddagger}$ & $\$ 1,555(8,547)^{\ddagger}$ & $\$ 1,548(7,785)^{\ddagger}$ \\
\hline Pharmacy & $\$ 896(2,554)$ & $\$ 1,016(2,487)^{\ddagger}$ & $\$ 1,051(2,457)^{\ddagger}$ & $\$ 1,102(2,524)^{\ddagger}$ \\
\hline
\end{tabular}

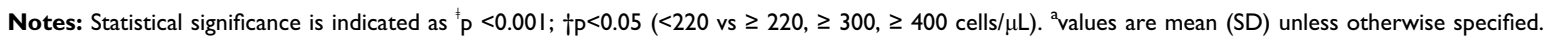

was associated with a $6.4 \%$ increase in all-cause cost, a $14.0 \%$ increase in hospital all-cause, and a $11.3 \%$ increase in overall COPD-related cost (Figure 4).

\section{Discussion}

The findings of this study indicate a relationship between blood eosinophil count and clinical outcomes, health care 


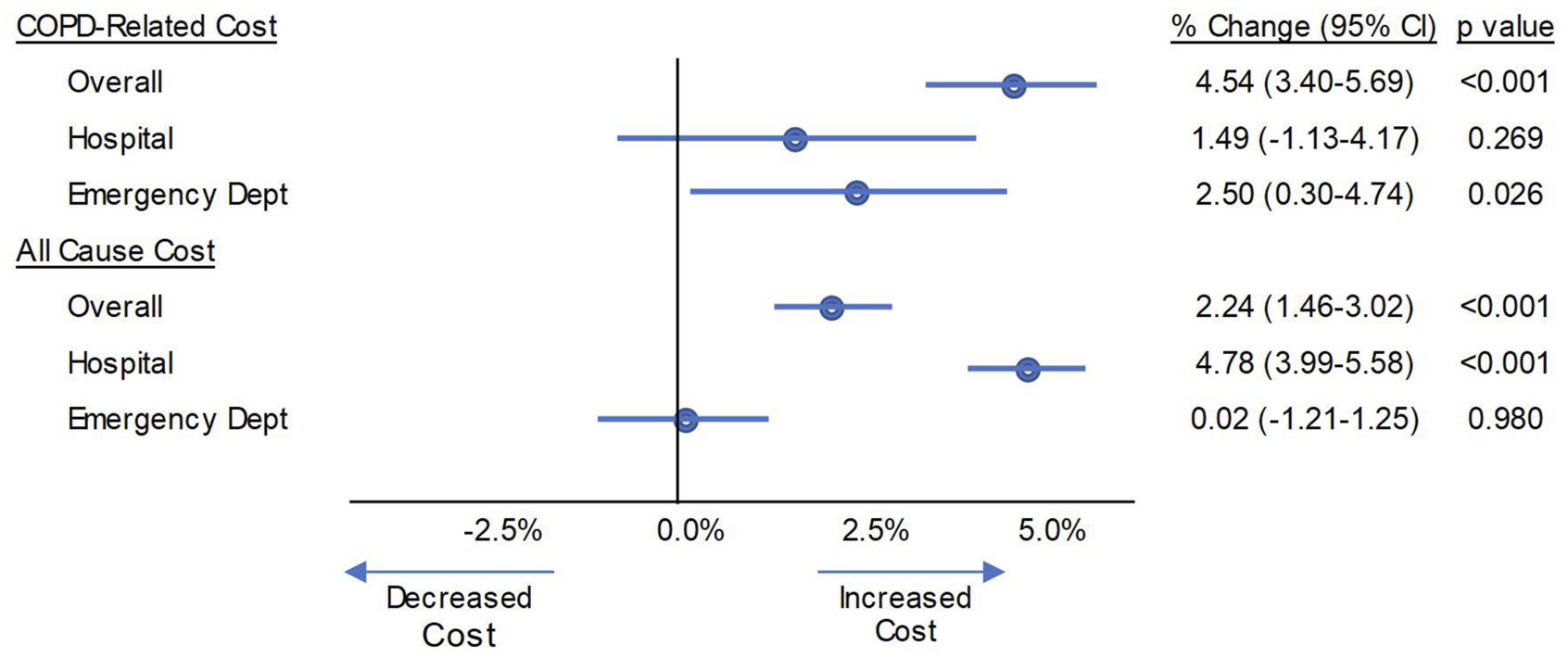

Figure 3 Adjusted percent change in COPD-related and all-cause annual healthcare cost for blood eosinophil count as a continuous measure.

Note: Adjusting for age, gender, smoking status, exacerbations, inhaled and systematic corticosteroid (ICS, SCS) treatment, Charlson comorbidity index (CCI), asthma, baseline COPD cost.

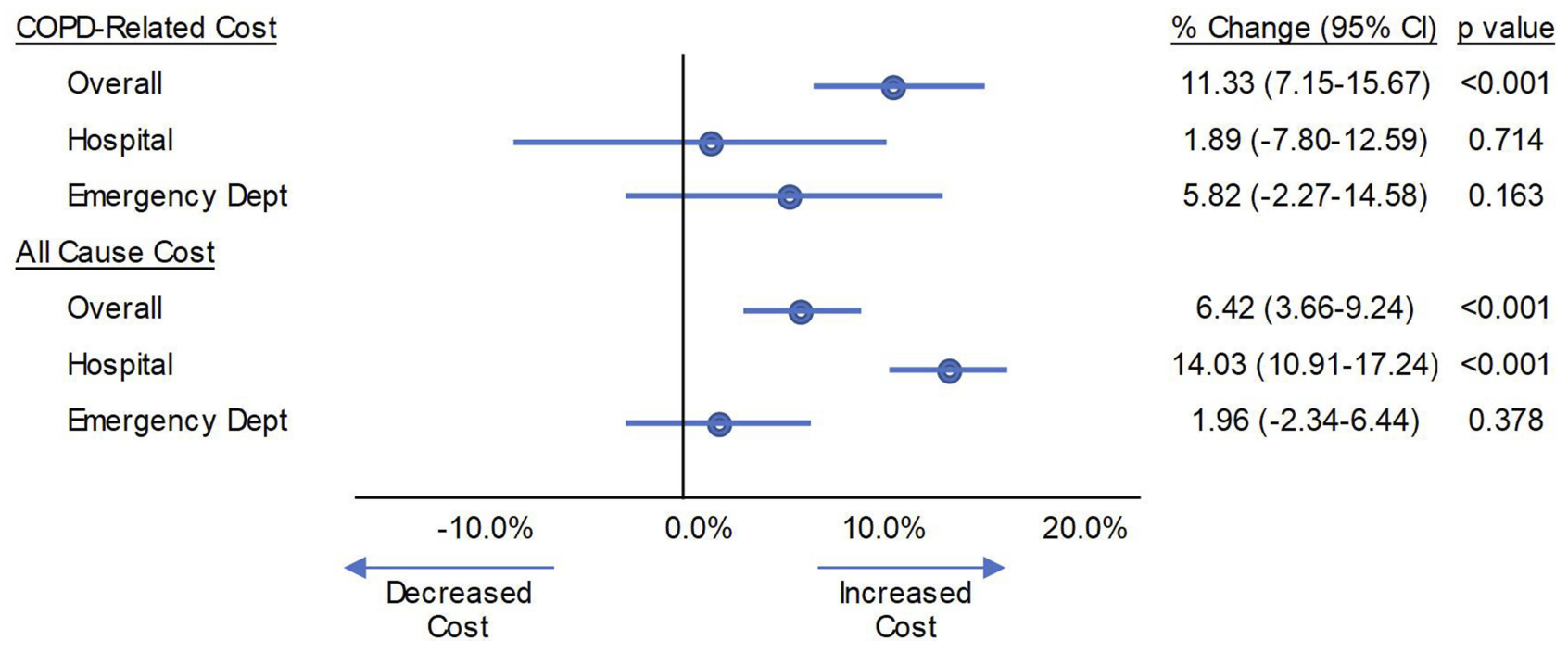

Figure 4 Adjusted percent change in COPD-related and all-cause annual healthcare cost for blood eosinophil count as a dichotomous measure, $<220$ cells $/ \mu \mathrm{L} \geq 220$ cells $/ \mu \mathrm{L}$. Note: Adjusting for age, gender, smoking status, exacerbations, inhaled and systematic corticosteroid (ICS, SCS) treatment, Charlson comorbidity index (CCI), asthma, baseline COPD cost.

resource utilization and cost in patients with COPD. Patients with COPD and a blood eosinophil count $\geq 220$ cells $/ \mu$ L were significantly more likely to have had moderate or severe exacerbations and greater cost of care than those with a blood eosinophil count of $<220$ cells $/ \mu \mathrm{L}$. Average all-cause cost and average COPD-related cost were greater for groups with greater absolute blood eosinophil counts. The relationship of blood eosinophil count to both all-cause and COPDrelated costs remained significant after adjustment for covariates. Blood eosinophil count demonstrated a predictive effect on both all-cause and COPD-related cost, with a greater impact on COPD-related cost than on all-cause cost. Frequencies of moderate and severe exacerbations were greater for groups with greater eosinophil counts.

This study is the largest currently known to the authors, which examines the effect of blood eosinophil count on health care resource utilization and cost in patients with COPD. A recent smaller study by Ortega et al showing a similar increase in cost with increasing blood eosinophil count was conducted utilizing data from a single US health care delivery system. ${ }^{12}$ 
In another recent study based on EMR data linked to claims with a large sample size across many care settings in the United States, Mullerova et al found that blood eosinophil counts $\geq 150$ cells $/ \mu \mathrm{L}$ were associated with increased HCRU and higher exacerbation rates compared with blood eosinophil counts $<150$ cells $/ \mu \mathrm{L} .{ }^{13}$ The current study has several strengths. Our study was based on a large population of COPD patients identified from a single ambulatory EMR system in use in all 50 states and includes linkage to a large transactional claims database that captures a large percentage of the prescription, medical, and hospital claims in the United States. Since the integrated study database captures both national EMR data and a large percentage of claims data across the United States the results may be more generalizable to the US COPD patient population than other, smaller studies. In addition, the cost evaluation in this study was based on use of an "open" set of claims generated from health care transactions for all patients with such health care transactions regardless of insurance plan, as opposed to a "closed" claims system, in which the claims come from a defined enrolled population in a single or set of health insurance plans. The average allcause cost and COPD-related costs in this study (\$21,409 to $\$ 26,199$ and $\$ 4,357$ to $\$ 5,774$ ) were similar to those found in a recent evaluation of COPD patients new to ICS/LABA therapy conducted for patients arising from a set of a 14 health plan (all-cause cost: $\$ 21,600$ to $\$ 24,500$ and COPD-related cost $\$ 4,300$ to $\$ 4,800$ ) suggesting that the open claims included in this analysis captured a high proportion of utilization for the included patients. ${ }^{16}$

Eosinophil counts related to asthma or other comorbidities are unlikely to explain the observed distribution of eosinophils. The percentages of patients with a diagnosis of comorbid asthma only increased slightly across eosinophil count subgroups, ranging from $17.1 \%$ to $21.3 \%$. Comorbidities were consistent with or lower than other COPD-defined cohorts and maintained their consistency across eosinophil counts. ${ }^{17}$ Numbers of comorbidities were relatively constant across eosinophil subgroups, with values of CCI ranging from 2.5 to 2.9. This suggests that the associated increase in costs is more likely due to the severity of COPD as opposed to the presence of comorbidities.

Absolute blood eosinophil counts were operationalized in a number of ways in this study (continuous metric, $\geq 220$ cells $/ \mu \mathrm{L}, \geq 300$ cells $/ \mu \mathrm{L}$, and $\geq 400$ cells $/ \mu \mathrm{L}$ ). Defining elevated eosinophil count using absolute counts of 220, 300 , and 400 cells $/ \mu \mathrm{L}$ is consistent with the range of definitions of elevated eosinophil count used in other studies that evaluated health outcomes for COPD patients.
For example, Hospers et al used a cutoff of 275 cells $/ \mu \mathrm{L}$ and Vedel-Krogh et al used a cutoff of 340 cells $/ \mu \mathrm{L}$. ${ }^{4,18}$ However, a study by Singh et al yielded approximately half of COPD patients with persistently low or high eosinophil counts, while the other half had variable eosinophil counts over a 3 -year period of time. ${ }^{19}$ Therefore, additional studies investigating in greater detail the dynamic nature of blood eosinophil counts over time in patients with COPD and their relationship to important clinical outcomes should be conducted.

For the regression models assessing the effect of eosinophil count on health resource utilization and cost, we used eosinophil count as either a continuous measure showing percentage change in cost for each 100 cells/ $\mu \mathrm{L}$ increase in eosinophil count or as a dichotomous measure based on the lowest of the three descriptive cutoffs $\geq 220$ cells $/ \mu \mathrm{L}$ compared to $<220$ cells $/ \mu \mathrm{L}$. Both COPD-related cost and allcause cost increased as blood eosinophil count increased, and this relationship of blood eosinophil count to cost was significant even when adjusted for covariates, including comorbidities such as asthma. Patients with COPD and blood eosinophil count $\geq 220$ cells $/ \mu \mathrm{L}$ were significantly more likely to have had moderate or severe exacerbations and greater cost of care than those with a blood eosinophil count $<220$ cells $/ \mu \mathrm{L}$. With a threshold of 220 cells $/ \mu \mathrm{L}$, nearly half $(44 \%)$ of this COPD cohort have an eosinophilic phenotype. When eosinophil count was modeled as a continuous measure there was an increase in cost based on every 100 cell $/ \mu \mathrm{L}$ increase in blood count, across the range of counts evaluated. This suggests a continuous relationship between cost and any increase in blood eosinophil counts similar to the continuous relationship between blood eosinophil counts and ICS effect described in the most recent GOLD report. ${ }^{10}$

These findings must be considered with respect to limitations of the secondary data utilized in this analysis. To account for COPD severity, we included prior COPD exacerbations from claims, baseline comorbidities and medication use, as clinical measures of COPD severity were not readily available in the EMR data used for our study population. Another potential limitation is that only $18 \%$ of the initial EMR COPD cohort had an available blood eosinophil count. Potential bias could result if only patients with more severe COPD received a complete blood count with differential.

\section{Conclusion}

We conclude that these data are sufficiently impactful to suggest that providers obtain eosinophil counts for COPD risk stratification when making decisions regarding ICS 
use. Further studies will be required to determine if treatment targeting eosinophils will impact costs and outcomes in patients with COPD. Our finding that nearly half of all COPD patients in this cohort had an eosinophilic phenotype suggests that future studies should include COPD exacerbations as an outcome measure and should investigate outcomes based on blood eosinophil counts.

\section{Acknowledgments}

This study was funded by AstraZeneca through a contract with Veradigm Health. The abstract of this paper was presented at the CHEST Annual Meeting 2018 as a poster presentation with interim findings. The poster's abstract was published in “CHEST 2018 Annual Meeting Abstracts" CHEST Volume 154, Issue 4, Supplement, Pages 753A-754A: https://doi.org/ $\underline{10.1016 / \text { j.chest.2018.08.679. }}$.

\section{Author Contributions}

All authors contributed toward data analysis, drafting and critically revising the paper, gave final approval of the version for publication, and agree to be accountable for all aspects of the work.

\section{Disclosure}

FT and YC are employees of AstraZeneca. LK, JV, AW, LS, and DO are employees of Practice Fusion, a division of Veradigm Health, which received funding from AstraZeneca to conduct the study. CS is a consultant for AstraZeneca, Glaxo Smith Kline, and Uptake Medical on the topic of COPD. CS has grants from the Alpha-1 Foundation, BTG, CSL Behring, Grifols, Novartis, Shire and Vertex in COPD. CS also reports personal fees, non-financial support from AstraZeneca and GlaxoSmithKline, non-financial support from Boehringer Ingelheim and grants from Novartis, outside the submitted work. The authors report no other conflicts of interest in this work.

\section{References}

1. Barnes PJ. Inflammatory mechanisms in patients with chronic obstructive pulmonary disease. J Allergy Clin Immunol. 2016;138(1):16-27. doi:10.1016/j.jaci.2016.05.011

2. Bafadhel M, Pavord ID, Russell REK. Eosinophils in COPD: just another biomarker? Lancet Respir Med. 2017;5(9):747-759. doi:10.1016/S2213-2600(17)30217-5

3. Pasquale MK, Sun SX, Song F, Hartnett HJ, Stemkowski SA. Impact of exacerbations on health care cost and resource utilization in chronic obstructive pulmonary disease patients with chronic bronchitis from a predominantly Medicare population. Int J Chron Obstruct Pulmon Dis. 2012;7:757-764. doi:10.2147/COPD.S36997
4. Vedel-Krogh S, Nielsen SF, Lange P, Vestbo J, Nordestgaard BG. Blood eosinophils and exacerbations in chronic obstructive pulmonary disease. The copenhagen general population study. Am J Respir Crit Care Med. 2016;193(9):965-974. doi:10.1164/rccm.201509-1869OC

5. Zeiger RS, Tran TN, Butler RK, et al. Relationship of blood eosinophil count to exacerbations in chronic obstructive pulmonary disease. J Allergy Clin Immunol Pract. 2018;6(3):944-954. doi:10.1016/j.jaip.2017.10.004

6. Kerkhof M, Sonnappa S, Postma DS, et al. Blood eosinophil count and exacerbation risk in patients with COPD. Eur Respir J. 2017;50 (1). doi:10.1183/13993003.00761-2017

7. Pavord ID, Chanez P, Criner GJ, et al. Mepolizumab for eosinophilic chronic obstructive pulmonary disease. N Engl J Med. 2017;377 (17):1613-1629. doi:10.1056/NEJMoa1708208

8. Ferguson GT, Rabe KF, Martinez FJ, et al. Triple therapy with budesonide/glycopyrrolate/formoterol fumarate with co-suspension delivery technology versus dual therapies in chronic obstructive pulmonary disease (KRONOS): a double-blind, parallel-group, multicentre, phase 3 randomised controlled trial. Lancet Respir Med. 2018;6(10):747-758. doi:10.1016/S2213-2600(18)30327-8

9. Bafadhel M, Peterson S, De Blas MA, et al. Predictors of exacerbation risk and response to budesonide in patients with chronic obstructive pulmonary disease: a post-hoc analysis of three randomised trials. Lancet Respir Med. 2018;6(2):117-126. doi:10.1016/S2213-2600(18)30006-7

10. Singh D, Agusti A, Anzueto A, et al. Global strategy for the diagnosis, management, and prevention of chronic obstructive lung disease: the GOLD science committee report 2019. Eur Respir J. 2019;53:5. doi:10.1183/13993003.00164-2019

11. Kerkhof M, Tran TN, Soriano JB, et al. Healthcare resource use and costs of severe, uncontrolled eosinophilic asthma in the UK general population (Supplement). Thorax. 2018;73(2):116-124. doi:10.1136/ thoraxjnl-2017-210531

12. Ortega H, Llanos JP, Lafeuille MH, et al. Burden of disease associated with a COPD eosinophilic phenotype. Int J Chron Obstruct Pulmon Dis. 2018;13:2425-2433. doi:10.2147/COPD.S170995

13. Müllerová H, Hahn B, Simard E, Mu G, Hatipoğlu U. Exacerbations and health care resource use among patients with COPD in relation to blood eosinophil counts. Int $J$ Chron Obstruct Pulmon Dis. 2019;14:683-692. doi:10.2147/COPD.S194367

14. Ferguson GT, Tashkin DP, Skärby T, et al. Effect of budesonide/ formoterol pressurized metered-dose inhaler on exacerbations versus formoterol in chronic obstructive pulmonary disease: the 6-month, randomized RISE (Revealing the impact of symbicort in reducing exacerbations in COPD) study. Respir Med. 2017;132:31-41. doi:10.1016/j.rmed.2017.09.002

15. Lipson DA, Barnhart F, Brealey N, et al. Once-daily single-inhaler triple versus dual therapy in patients with COPD. $N$ Engl J Med. 2018;378(18):1671-1680. doi:10.1056/NEJMoa1713901

16. Davis JR, Kern DM, Williams SA, et al. Health care utilization and costs after initiating budesonide/formoterol combination or fluticasone/salmeterol combination among COPD patients new to ICS/ LABA treatment. J Manag Care Spec Pharm. 2016;22(3):293-304. doi:10.18553/jmcp.2016.22.3.293

17. Dal Negro RW, Bonadiman L, Turco P. Prevalence of different comorbidities in COPD patients by gender and GOLD stage. Multidiscip Respir Med. 2015;10(1):24. doi:10.1186/s40248-015-0023-2

18. Hospers JJ, Schouten JP, Weiss ST, Postma DS, Rijcken B. Eosinophilia is associated with increased all-cause mortality after a follow-up of 30 years in a general population sample. Epidemiology. 2000;11(3):261-268. doi:10.1097/00001648-200005000-00006

19. Singh D, Kolsum U, Brightling CE, Locantore N, Agusti A, TalSinger R. Eosinophilic inflammation in COPD: prevalence and clinical characteristics. Eur Respir J. 2014;44(6):1697-1700. doi:10.1183/09031936.00162414 


\section{Publish your work in this journal}

The International Journal of COPD is an international, peer-reviewed journal of therapeutics and pharmacology focusing on concise rapid reporting of clinical studies and reviews in COPD. Special focus is given to the pathophysiological processes underlying the disease, intervention programs, patient focused education, and self management

protocols. This journal is indexed on PubMed Central, MedLine and CAS. The manuscript management system is completely online and includes a very quick and fair peer-review system, which is all easy to use. Visit http://www.dovepress.com/testimonials.php to read real quotes from published authors.

Submit your manuscript here: https://www.dovepress.com/international-journal-of-chronic-obstructive-pulmonary-disease-journal 